\title{
Obesity indices as a risk factor of skin diseases: A Case-control study conducted in Cairo, Egypt
}

\author{
Raed M Alazab ${ }^{1}$, Abdel Raouf M Almohsen²
}

${ }^{1}$ Professor of Environmental and Occupational medicine, Department of Community Medicine and Occupational Medicine; ${ }^{2}$ Professor of Dermatology, Venereology and Andrology; Faculty of Medicine, Alazhar University, Cairo, Egypt.

\begin{abstract}
Overweight and obesity are two major health problems that have been recognized worldwide which affect all ages and have many negative health effects. WHO in year 2010 reported that in Egypt the prevalence of overweight among women is $76 \%$ compared to $64.5 \%$ for male while the prevalence of obesity among women is $48 \%$ compared to $22 \%$ for male. The aim of the study was to determine the most prevalent skin diseases among the studied overweight and obese patients and to examine if overweight and obesity are risk factors for skin diseases. A case-control was carried out on 250 overweight and obese patients compared with another 250 normal weight patients as controls. The participants were selected from the outpatient dermatology clinic of Al Hussein University hospital, Faculty of medicine, Alazhar University, Egypt. All patients were subjected to medical history, clinical dermatological examination and measurement of obesity indices. The most prevalent skin diseases among the studied cases were: striae (68.4\%), planter hyperkeratosis $(61.6 \%)$, skin tags $(61.2 \%)$, acanthosis nigricans $(53.6 \%)$, intertrigo $(53.6 \%)$, tinea pedis $(41.2 \%)$ with statistical significance difference compared to controls. As a result, overweight and obesity might be a risk factor for some skin diseases. Dermatologists must work with primary health care physicians and nutritional specialists to reduce incidence of obesity or reduce the effects of obesity on the skin.
\end{abstract}

Keywords: Obesity, risk factors, Skin diseases, Case-control study, Egypt.

\section{Introduction}

The World Health Organization (WHO) defines overweight and obesity as 'abnormal or excessive fat accumulation that may impair health. Body mass index (BMI) - the weight in kilograms divided by the square of the height in meters $\left(\mathrm{kg} / \mathrm{m}^{2}\right)$ - is a commonly used index to classify overweight and obesity in adults. ${ }^{1}$ WHO defines overweight as a BMI equal to or more than 25, and obesity as a BMI equal to or more than 30. ${ }^{1}$ WHO global estimates in 2008 indicated that more than 1.4 billion adults, 18 years and older were overweight and more than half a billion were obese and the prevalence of obesity has nearly doubled globally between 1980 and 2008. Once associated with high-income countries, obesity is now also prevalent in low- and middle-income countries and at least 2.8 million people each year dies as a result of being overweight or obese. ${ }^{1}$ Australia, UK, and USA among high-income countries while Mexico, Egypt and South Africa among lower- and middle-income countries have the higher number of overweight and obese people. ${ }^{2}$ It is estimated that in 2030 an estimated 2.16 billion adults worldwide will be overweight and 1.12 billion will be obese. ${ }^{3}$

Obesity has become an epidemic in many parts of the world. WHO has warned of the escalating epidemic of obesity that could put the population in many countries at risk of developing long-term non-communicable diseases (NCD). Available studies in the Eastern Mediterranean countries indicated that obesity had reached at an alarming level among both children and adults. ${ }^{4}$ In Egypt,

\section{Practice Points}

- Dermatological changes have been reported in patients with obesity.

- The most common skin diseases among obese patients were striae, planter hyperkeratosis, skin tags, acanthosis nigricans, intertrigo, tinea pedis.

- The odds ratio of the following diseases in obese patients were: planter hyperkeratosis (42.9), intertrigo (16.9), striae (14.7), varicose vein (14.3), skin tag (8.5), psoriasis (4.03) and hirsutism (3.9).

- Statistical significance difference were noted between obese patients and control groups in tinea pedis, planter wart, striae, intertrigo, skin tag, planter hyperkeratosis, varicose vein, hirsutism and psoriasis.

- Dermatologists must work with primary health care physicians and nutritional specialists to reduce incidence of obesity or reduce the effects of obesity on the skin.

2010 WHO estimated the prevalence rate of overweight among women was $75.3 \%$ compared to $60.4 \%$ for male, and the prevalence of obesity among women is $44.5 \%$ compared to $21.4 \%$ for male. ${ }^{5}$

Correspondence: Prof. Raed M Alazab, Department of Community Medicine and Occupational Medicine, College of Medicine, Alazhar University, Cairo, Egypt. Email: raedelazab@hotmail.com. 
Obesity is a health problem of considerable magnitude in the western world. Dermatological changes have been reported in patients with obesity, including: acanthosis nigricans and skin tags (due to insulin resistance), hyperandrogenism, striae due to over extension, stasis pigmentation due to peripheral vascular diseases, lymphedema, pathologies associated with augmented folds, morphologic changes in the foot anatomy due to excess load, and complications that may arise from hospitalization. ${ }^{6}$

The aim of the present study were to determine more prevalent skin diseases among the overweight and obese patients people and to examine if overweight and obesity are risk factors for skin diseases.

\section{Materials and methods}

\section{Type of the study:}

A case-control study was conducted during the period from February 2012 to April 2013. This study was carried out on 250 overweight or obese patients as a cases group and another 250 normal weight patients were included as a control group.

\section{Sample size estimation of the studied patients:}

The sample size was estimated by using program Epi Info version 7.1.2.0, 2013, CDC, USA. The following are data used to calculate the minimum sample size required: confidence level $(99.9 \%)$, power $(80 \%)$, and ratio of control: cases (1:1), percentage of control exposed (40\%) and odds ratio (2.25). Minimum sample size estimated was 222 per each group of cases and controls. Sample size increased by about $10 \%$ to overcome non-responses.

\section{Place and Selection of patients:}

All patients of the study were selected from the outpatient dermatology clinic of Al Hussein University hospital, Faculty of medicine, Alazhar University, Egypt. Exclusion criterion included were: patients below age of 18 years and any patient with any diseases other than dermatological origin.

\section{Sampling technique:}

A simple random sampling technique was used to select the included cases and controls. The outpatient clinic was visited 5 days/week (from 9am to $12 \mathrm{pm}$ ) for a period of 8 months. All cases and controls who met the inclusion criteria were taken into a list. They were numbered chronologically using a random table and a total of 500 (250 cases and 250 controls) respondents were selected.

\section{Ethical consideration:}

The protocol of the study was first presented to the staff of the Department of Dermatology, Venereology and Andrology, Faculty of Medicine, Alazhar University and then the department approved the study. Finally, the protocol was got ethical clearance from the
Committee of Medical Ethics at Faculty of Medicine, Alazhar University. An oral consent from every participant was taken for participation in the study. Ethical guidelines on research produced by the Declaration of Helsinki (updated 2008) was considered and applied during the period of the study.

\section{History/Physical examination:}

All patients were subjected to the following:

i. Medical history:

- Personal history including: age, sex, residence, marital status and occupation.

- Present and past history: to exclude any nondermatological disease.

ii. Obesity measurements:

Weight: Subjects were weighed in kilograms.

Height: Standing body height in meter $(\mathrm{BH})$ was measured without shoes with the shoulders in relaxed position and arms hanging free.

Body mass index (BMI): which is calculated by dividing a patient's weight by his squared height $\left(\mathrm{kg} / \mathrm{m}^{2}\right)$. The following categories were used: The normal weight patients (body mass index (BMI) less than 25), the overweight patient (body mass index (BMI) equal to 25 -29.9) and the obese patient (body mass index (BMI) equal to or higher than 30), obese group was further divided into three BMI classes: class I (BMI 30-34.9), class II (BMI 35-39.9) and class III $(\mathrm{BMI} \geq 40){ }^{1}$

Waist circumference: The range of normal, high and very high waist circumference among male and female participants are shown in Table 1. During the examination, the individual stand with feet close together, arms at the side and body weight evenly distributed, and relaxed, and the measurement taken at the end of a normal expiration, the tape measure placed directly on skin, waist circumference measured at the midpoint between the lower margin of the last palpable rib and the top of the iliac crest. ${ }^{8}$

Hip circumference: Hip circumference was measured around the widest portion of the buttocks, with the tape parallel to the floor. ${ }^{8}$

Waist/Hip ratio:

This was calculated by dividing a patient's waist circumference by their hip circumference (Table 2). ${ }^{8}$

Table 1: Range of waist circumference among male and female participants

\begin{tabular}{|l|c|c|c|}
\hline \multirow{2}{*}{ Sex } & \multicolumn{3}{|c|}{ Waist circumference } \\
\cline { 2 - 4 } & Normal & High & Very High \\
\hline Male & $<94$ & $94-102$ & $\geq 102$ \\
\hline Female & $<80$ & $80-88$ & $\geq 88$ \\
\hline
\end{tabular}


Table 2: Acceptable and non-acceptable Waist/Hip ratio among male and female participants ${ }^{8}$

\begin{tabular}{|l|c|c|c|c|c|}
\hline \multirow{2}{*}{ Sex } & \multicolumn{2}{|c|}{ Acceptable } & \multicolumn{2}{c|}{ Non Acceptable } \\
\cline { 2 - 6 } & Excellent & Good & Average & High & Extreme \\
\hline Male & 0.83 & $0.85-0.90$ & $0.90-0.95$ & $0.95-1.00$ & $>1.00$ \\
\hline Female & 0.75 & $0.75-0.80$ & $0.80-0.85$ & $0.85-0.90$ & $>0.90$ \\
\hline
\end{tabular}

\section{iii. Complete dermatological examination:}

The examination was conducted using the following as per guidelines: ${ }^{7}$

- Observing the overall appearance of the patient and skin. Is the patient healthy or ill-appearing? Is there an abnormal color to the skin?

- Inspecting each part of the body. A head-to-toe approach was done:

- Scalp and hair: If the patient has a full head of hair, we may need to part it in several areas to see the scalp well. Hair bands should be removed so that the hair is loose.

- Face, including eyes, nose, and mouth: In the nose, examine the outer nostrils and the nasal septum (using a flashlight). Mouth findings are often subtle and we should always use a flashlight here. The patient was advised to move the tongue to either side so that the inner cheeks can be visualized; also inspection of the palate and all surfaces of the tongue were done

- Ears and neck: Inspection of the outer ear, the external ear canal and behind the ears. After examining the neck, feel for any enlarged lymph nodes locally, as well as elsewhere.

- Chest and abdomen: Inspection of the axillae and under the breasts, and in skin folds of obese patients.

- Back and buttocks: Examining the intergluteal cleft and perianal region.

- Arms, hands, fingernails: Inspection of the sides of the fingers and web spaces, and distinguish lesions on the dorsum of the hand from those on the palms. When examining nails also looking at the surrounding (periungual) area and the cuticles.

- Legs, feet, toenails: The groin folds was inspected at this time. Examining the feet in the same manner as the hands, including interdigital areas and the soles.

- Genitalia. Inspection of the pubic area and labia in women, and the pubic area, scrotum and penis in men.

\section{Statistical analysis:}

Analysis of data was conducted by using Epi info program on Microsoft windows of personal computer.
The collected data were coded, entered, analyzed and tabulated. Range, Mean $\pm \mathrm{SD}, \mathrm{t}$ test, odds ratio $(\mathrm{OR})$ and $\operatorname{chi}^{2}$ were the statistical methods used during the analysis of data of the present study. A $p$ value $<0.05$ was considered as the accepted level of significance.

\section{Results}

The socio-demographic characteristics of the studied subjects are shown in Table 3. It was found that $14 \%$ and $15 \%$ of cases and controls were males respectively $(p>0.05)$ although the age range of both groups was 18 to 60 years old. Majority of the studied subjects in both groups were married, house wives and nonsmokers.

Table 4 shows that the most common skin diseases among cases were tinea pedis $(41.2 \%)$, hair dandruff $(26.8 \%)$, striae $(68.4 \%)$, intertrigo $(53.6 \%)$, skin tag $(61.2 \%)$, planter hyperkeratosis $(61.6 \%)$, and acanthosis negricans (53.6\%). Among the controls, the common skin diseases included: hair dandruff $(28 \%)$, acne $(14 \%)$, tinea pedis $(18 \%)$, callosity $(11.2 \%)$, striae $(12.8 \%)$ and skin tag (15.6\%). It was found that Odds ratio of the following diseases in cases were; planter hyperkeratosis (42.9), intertrigo (16.9), striae (14.7), varicose vein (14.3), skin tag (8.5), psoriasis (4.03) and hirsutism (3.9).

Table 5 shows the following measurements among the cases: mean BMI $32.4 \pm 4.2$; mean hip circumference, male $104.5 \pm 0.6$ and female $92.9 \pm 0.2$; mean waist circumference, male was $98.9 \pm 0.2$ and female was $91.3 \pm 0.3$; and mean Waist/Hip ratio, male $0.94 \pm 0.02$ and female $0.86 \pm 0.2$. The measurements among controls were: mean BMI 22.4 \pm 1.6 ; mean hip circumference, male $92.9 \pm 0.9$ and female $95.3 \pm 0.1$; and mean waist circumference, male $82.2 \pm 0.3$; female $75.9 \pm 0.2$; and mean Waist/Hip ratio, male $0.88 \pm 0.1$ and female was $0.79 \pm 0.3$. It was found that there was statistical significance difference between both groups as regards all obesity measurements.

Table 6 shows the comparison between controls and every category of BMI. It was observed that there was statistical significance difference between cases and control groups as regards the following skin diseases: tinea pedis $(p-0.00)$ in categories of overweight, obese class 1 and obese class 2; planter wart $(p-0.01)$ in categories of obese class 1 ; striae $(p-0.00)$, intertrigo ( $p$ $0.00)$, skin tag $(p-0.00)$, planter hyperkeratosis $(p-$ $0.00)$, varicose vein $(p-0.00)$, hirsutism $(p-0.00)$ in categories of overweight, obese class 1 and obese class 2; and psoriasis in categories of overweight and obese class $2(p-0.00)$ and in obese class $1(p-0.01)$. 
Table 3: Socio-demographic characteristics of the studied groups

\begin{tabular}{|c|c|c|c|}
\hline Socio-Demographic & $\begin{array}{c}\text { Cases group } \\
\mathrm{N}=\mathbf{2 5 0}\end{array}$ & $\begin{array}{c}\text { Control group } \\
\mathbf{N}=\mathbf{2 5 0}\end{array}$ & $p$-value \\
\hline $\begin{array}{l}\text { Age } \\
\text { Range (years) } \\
\text { Mean } \pm \text { SD }\end{array}$ & $\begin{array}{c}25-60 \\
39.2 \pm 6.8\end{array}$ & $\begin{array}{c}18-60 \\
33.4 \pm 7.8\end{array}$ & $0.00 *$ \\
\hline $\begin{array}{l}\text { Sex } \\
\quad \text { Male } \\
\text { Female }\end{array}$ & $\begin{array}{c}36(14.4 \%) \\
214(85.6)\end{array}$ & $\begin{array}{c}38(15.2 \%) \\
212(84.8 \%)\end{array}$ & 0.8 \\
\hline $\begin{array}{l}\text { Marital status } \\
\text { Married } \\
\text { Single }\end{array}$ & $\begin{array}{c}242(96.8 \%) \\
8(3.2 \%)\end{array}$ & $\begin{array}{c}174(69.6 \%) \\
76(30.4 \%)\end{array}$ & $0.00 *$ \\
\hline $\begin{array}{l}\text { Occupation } \\
\text { House wife } \\
\text { Housekeeper } \\
\text { Student } \\
\text { Technician } \\
\text { Accountant } \\
\text { Plummer } \\
\text { Employee } \\
\text { Worker } \\
\text { Electricity technician }\end{array}$ & $\begin{array}{c}165(66.0 \%) \\
23(9.2 \%) \\
3(1.2 \%) \\
0(0 \%) \\
6(2.4 \%) \\
7(2.8 \%) \\
34(13.6 \%) \\
4(1.6 \%) \\
8(3.2 \%) \\
\end{array}$ & $\begin{array}{c}126(50.4 \%) \\
4(1.6 \%) \\
54(21.6 \%) \\
3(1.2 \%) \\
9(3.6 \%) \\
5(2 \%) \\
32(12.8 \%) \\
11(4.4 \%) \\
6(2.4 \%) \\
\end{array}$ & $0.00^{*}$ \\
\hline $\begin{array}{l}\text { Smoking } \\
\quad \text { Smokers } \\
\text { Non smokers }\end{array}$ & $\begin{array}{c}36(14.4 \%) \\
214(85.6 \%)\end{array}$ & $\begin{array}{c}38(15.2 \%) \\
212(84.8 \%)\end{array}$ & 0.8 \\
\hline
\end{tabular}

*Significant

\section{Discussion}

The present study found that the most prevalent skin diseases among cases group included striae (68.4\%, OR $14.7)$, planter hyperkeratosis $(61.6 \%$, OR 42.9$)$, skin tags (61.2\%, OR 8.5), acanthosis nigricans (53.6\%, $0.0 \%$ among controls), intertrigo (53.6\%, OR 16.9), and tinea pedis $(41.2 \%$, OR 3.2) (Table 4).

The striae (68.4\%), the most prevalent disease, might be related to excessive tension on the skin caused by excessive body weight. ${ }^{18}$ However, a higher prevalence rate was observed among obese adults in Mexico $(89 \%),{ }^{8}$ but a lower prevalence was reported in studies a Taiwan $(40 \%)^{9}$ and Kuwait $(23.3 \%){ }^{10}$ These variation could be attributed to different sample size, ethnic groups or female to male ratio among the studied cases.

It was noticed in the present study that the prevalence rate of planter hyperkeratosis was ranked as the second most common skin disease $(61.6 \%$. It is considered as a stigma of morbid obesity resulting from the effect of the pressure of excess weight. It was found that the prevalence rate of planter hyperkeratosis in the present study lower than that reported among obese adults in Mexico $(75.2 \%)^{8}$ but higher than those shown in Brazil $(46.7 \%),{ }^{11}$ and Kuwait (45.1\%). ${ }^{10}$ Skin tags $(61.2 \%)$ in the present study were found to be lower than that reported among obese adults in the USA (74\%), ${ }^{12}$ but higher than those shown in Brazil $(47.94 \%))^{11}$ and Kuwait (30\%). ${ }^{10}$

Acanthosis nigricans (hyperpigmented velvety cutaneous thickening affecting localized areas of the skin) is frequently associated with obesity, endocrinopathies, malignancy, genetic syndromes and some drugs use. ${ }^{13}$ Acanthosis nigricans in the present study was prevalent among $53.6 \%$ of the studied group, which was lower than the findings from studies conducted in Brazil (76\%), ${ }^{11}$ USA (74\%), ${ }^{12}$, and Mexico $(64.2 \%),{ }^{8}$ but higher than those found in Kuwait $(33 \%)$ 10, and Saudi Arabia(14.1\%). ${ }^{15}$ This variation in prevalence rate might be attributed to the variation of age groups and the severity of obesity among the subjects of the mentioned studies. The prevalence rate of intertrigo $(53.6 \%)$ was higher than the findings observed in Iraq (52\%), ${ }^{16}$ Brazil (44.7\%), ${ }^{11}$ and Kuwait (22.2\%). ${ }^{10}$

The present study found that the prevalence of tinea pedis was $(41.2 \%)$ however, a lower prevalence rate $(1.9 \%)$ was reported in a study in USA. Patients were randomly invited to have an additional examination of their feet, obesity was one of the three most prevalent predisposing factors among the examined patients. ${ }^{24}$ The prevalence rate of hair dandruff $(26.8 \%)$ among cases group was higher than what was reported in Saudi Arabia study $(23.8 \%)^{15}$ and hirsutism $(15.2 \%)$ was lower than the findings observed in Kuwait $(15.8 \%) .{ }^{10}$ It was observed in one study that the facial hirsutism is significantly correlated with BMI independently of age and testosterone level. ${ }^{17}$ They demonstrated that 74 of the obese patients were diagnosed as having polycystic ovary syndrome, 69 of them were hirsute, 43 also had acne, and 26 had acanthosis nigricans. ${ }^{17}$

The prevalence of superficial varicose vein in the present study was (14.8\%); a study in Belgrade comprised 1116 subjects with primary chronic superficial varicose veins; $384(34.4 \%)$ men and 732 $(65.6 \%)$ women found that; $464(41.6 \%)$ were normalweight patients, $476(42.7 \%)$ were overweight and 176 $(15.8 \%)$ were obese. ${ }^{25}$ 
Table 4: Prevalence of skin diseases among the studied groups

\begin{tabular}{|c|c|c|c|c|c|}
\hline Skin Diseases & $\begin{array}{c}\text { Cases group } \\
\mathbf{N}=\mathbf{2 5 0}\end{array}$ & $\begin{array}{c}\text { Control group } \\
\mathbf{N}=\mathbf{2 5 0}\end{array}$ & chi-square & $p$-value & $\begin{array}{c}\text { Test of } \\
\text { significance }\end{array}$ \\
\hline Planter wart & $4(1.6 \%)$ & $21(8.4 \%)$ & 25.0 & $0.00 *$ & 0.2 \\
\hline Vitilligo & $0(0 \%)$ & $4(1.6 \%)$ & $\mathrm{N} / \mathrm{A}$ & - & - \\
\hline Acne & $28(11.2 \%)$ & $35(14 \%)$ & 0.89 & 0.34 & 0.9 \\
\hline Tinea pedis & $103(41.2 \%)$ & $45(18 \%)$ & 32.29 & $0.00 *$ & 3.2 \\
\hline Hair dandruff & $67(26.8 \%)$ & $70(28 \%)$ & 0.09 & 0.76 & 0.9 \\
\hline Generalized hair falling & $4(1.6 \%)$ & $19(7.6 \%)$ & 10.25 & $0.00 *$ & 0.2 \\
\hline Scabies & $4(1.6 \%)$ & $18(7.2 \%)$ & 9.32 & $0.00 *$ & 0.2 \\
\hline Callosity & $29(11.6 \%)$ & $28(11.2 \%)$ & 0.02 & 0.88 & 1.04 \\
\hline Milaria & $0(0 \%)$ & $3(1.2 \%)$ & N/A & - & - \\
\hline Striae & $171(68.4 \%)$ & $32(12.8 \%)$ & 160.23 & $0.00 *$ & 14.7 \\
\hline Intertrigo & $134(53.6 \%)$ & $16(6.4 \%)$ & 132.61 & $0.00 *$ & 16.9 \\
\hline Tinea versicolour & $0(0 \%)$ & $2(0.8 \%)$ & $\mathrm{N} / \mathrm{A}$ & - & - \\
\hline Skin tag & $153(61.2 \%)$ & $39(15.6 \%)$ & 109.88 & $0.00 *$ & 8.5 \\
\hline Tinea corporis & $0(0 \%)$ & $2(0.8 \%)$ & $\mathrm{N} / \mathrm{A}$ & - & - \\
\hline Planter hyperkeratosis & $154(61.6 \%)$ & $9(3.6 \%)$ & 191.38 & $0.00 *$ & 42.9 \\
\hline Hair pediculosis & $4(1.6 \%)$ & $12(4.8 \%)$ & 4.13 & $0.00 *$ & 0.3 \\
\hline Hidradenitis suppurativa & $3(1.2 \%)$ & $0(0 \%)$ & N/A & - & - \\
\hline Acanthosis negricans & $134(53.6 \%)$ & $0(0 \%)$ & $\mathrm{N} / \mathrm{A}$ & - & - \\
\hline Lymphedema & $13(5.2 \%)$ & $0(0 \%)$ & $\mathrm{N} / \mathrm{A}$ & - & - \\
\hline Onychomycosis & $2(0.8 \%)$ & $0(0 \%)$ & N/A & - & - \\
\hline Superficial Varicose vein & $37(14.8 \%)$ & $3(1.2 \%)$ & 31.41 & $0.00 *$ & 14.3 \\
\hline Hirsutism & $38(15.2 \%)$ & $11(4.4 \%)$ & 16.49 & $0.00 *$ & 3.9 \\
\hline Ptyriasis rosea & $2(0.8 \%)$ & $2(0.8 \%)$ & N/A & - & - \\
\hline Alopecia areata & $2(0.8 \%)$ & $5(2 \%)$ & 1.30 & 0.25 & 0.4 \\
\hline Psoriasis & $26(10.4 \%)$ & $7(2.8 \%)$ & 11.71 & $0.00^{*}$ & 4.03 \\
\hline Plane wart & $0(0 \%)$ & $1(0.4 \%)$ & $\mathrm{N} / \mathrm{A}$ & - & - \\
\hline Tinea cruris & $3(1.2 \%)$ & $3(1.2 \%)$ & N/A & - & - \\
\hline Urticaria & $0(0 \%)$ & $4(1.6 \%)$ & N/A & - & - \\
\hline Hyperhydrosis & $0(0 \%)$ & $2(0.8 \%)$ & $\mathrm{N} / \mathrm{A}$ & - & - \\
\hline Folliculitis & $4(1.6 \%)$ & $0(0 \%)$ & N/A & - & - \\
\hline Contact dermatitis & $1(0.4 \%)$ & $0(0 \%)$ & N/A & - & - \\
\hline
\end{tabular}

OR: Odds Ratio

The prevalence of acne in the present study was $(11.2 \%)$, which was lower than what were reported in the Kuwait $(21.5 \%),{ }^{10}$ Mexico $(25.1 \%){ }^{6}$ and Saudi $(19.4 \%)^{15}$ studies. The authors of the Saudi study concluded that acne was associated with insulin resistance and hyperandrogenism and was the most common skin condition among the overweight and obese schoolchildren. ${ }^{15}$

The prevalence rate of psoriasis in the present study was $(10.4 \%)$, which was lower than what reported from Brazil (13.2\%), ${ }^{11}$ but higher than those shown in Kuwait $(6.4 \%) .{ }^{10}$ It was found in a 10 -year study that elevated BMI $(>25)$ was significantly associated with long-term prognosis of psoriasis ${ }^{19}$ while Naldi et al., ${ }^{20}$ reported that clinical obesity (BMI >29) formulate more than double the risk of psoriasis. Psoriasis has been recognized as a systemic disease associated with metabolic syndrome, type-2 diabetes, dyslipidemia, hypertension and obesity. There is also evidence that being overweight is a risk factor for the onset of psoriasis and that the BMI is correlated with the PASI (Psoriasis Area and Severity Index). ${ }^{21,22}$

The prevalence of lymphedema in the present study was $(5.2 \%)$, which was lower than what was reported from
Brazil $(12.32 \%)^{11}$. This could be explained with the lower number of cases of obesity grade 3 among cases group $(10 \%)$ and no cases among control group. It was conclude in a French study that morbid obese patients showed the positive correlation between obesity and lymphedema. ${ }^{23}$

The study has also a number of limitations. All cases and controls were residents at one area surrounding the university hospital (where the cases and controls were selected) and also nearly of the same socioeconomic status, so the findings of the study should be generalize with caution. The study also conducted with a small sample size. Large-scale multi-centered follow-up studies should be conducted to identify the skin diseases and related complications among obese patients.

\section{Conclusion}

Overweight and obesity might be a risk factor for some skin diseases. The most common skin diseases among obese patients were striae, planter hyperkeratosis, skin tags, acanthosis nigricans, intertrigo, tinea pedis. The odds ratio of the following diseases in obese patients were: planter hyperkeratosis (42.9), intertrigo (16.9), striae (14.7), varicose vein (14.3), skin tag (8.5), psoriasis (4.03) and hirsutism (3.9). Statistical 
Table 5: Obesity measurements among the studied groups

\begin{tabular}{|c|c|c|c|c|}
\hline Obesity measurements & $\begin{array}{c}\text { Cases group } \\
\mathbf{N}=250\end{array}$ & $\begin{array}{c}\text { Control group } \\
\mathbf{N}=\mathbf{2 5 0}\end{array}$ & $\begin{array}{c}\text { Test of } \\
\text { significance }\end{array}$ & $p$-value \\
\hline $\begin{array}{l}\text { Weight }(\mathrm{kg}) \\
\text { Range } \\
\text { Mean } \pm \mathrm{SD}\end{array}$ & $\begin{array}{c}64: 118 \\
90.2 \pm 11.8\end{array}$ & $\begin{array}{c}50: 78 \\
62.9 \pm 5.6\end{array}$ & $\mathrm{~T}$ test $=33.0$ & $0.00 *$ \\
\hline $\begin{array}{l}\text { Height } \\
\quad \text { Range } \\
\quad \text { Mean } \pm \text { SD } \\
\end{array}$ & $\begin{array}{c}154: 179 \\
166.7 \pm 4.4\end{array}$ & $\begin{array}{c}157: 179 \\
167.8 \pm 5.8\end{array}$ & $\mathrm{~T}$ test $=2.3$ & $0.00 *$ \\
\hline $\begin{array}{l}\text { BMI } \\
\quad \text { Average } \\
\text { Overweight } \\
\text { Obese } 1 \\
\text { Obese } 2 \\
\text { Obese } 3 \\
\text { Range } \\
\text { Mean } \pm \text { SD } \\
\end{array}$ & $\begin{array}{c}0 \\
80(32 \%) \\
98(39.2 \%) \\
47(18.8 \%) \\
25(10 \%) \\
25.1: 43.9 \\
32.4 \pm 4.2 \\
\end{array}$ & $\begin{array}{c}250(100 \%) \\
0 \\
0 \\
0 \\
0 \\
18.6: 24.9 \\
22.4 \pm 1.6 \\
\end{array}$ & $\mathrm{~T}$ test $=35.4$ & $0.00 *$ \\
\hline $\begin{array}{l}\text { Hip circumference } \\
\text { Male } \\
\text { Range } \\
\text { Mean } \pm \text { SD }\end{array}$ & $\begin{array}{c}N=36 \\
95: 111 \\
104.5 \pm 0.6\end{array}$ & $\begin{array}{c}\mathrm{N}=38 \\
88: 99 \\
92.9 \pm 0.9\end{array}$ & $\mathrm{~T}$ test $=24.0$ & $0.0^{*}$ \\
\hline $\begin{array}{l}\text { Female } \\
\text { Range } \\
\text { Mean } \pm \mathrm{SD} \\
\end{array}$ & $\begin{array}{c}\mathrm{N}=214 \\
94: 127 \\
99.9 \pm 0.2 \\
\end{array}$ & $\begin{array}{c}N=212 \\
90: 98 \\
95.3 \pm 0.1\end{array}$ & $\mathrm{~T}$ test $=50.0$ & $0.0^{*}$ \\
\hline $\begin{array}{l}\text { Waist circumference } \\
\text { Male } \\
\text { Range } \\
\text { Mean } \pm \text { SD }\end{array}$ & $\begin{array}{c}N=36 \\
89: 108 \\
98.9 \pm 0.2\end{array}$ & $\begin{array}{c}\mathrm{N}=38 \\
79: 88 \\
82.2 \pm 0.3\end{array}$ & $\mathrm{~T}$ test $=36.0$ & $0.0 *$ \\
\hline $\begin{array}{l}\text { Female } \\
\text { Range } \\
\text { Mean } \pm \mathrm{SD} \\
\end{array}$ & $\begin{array}{c}\mathrm{N}=214 \\
78: 108 \\
91.3 \pm 0.3\end{array}$ & $\begin{array}{c}N=212 \\
70: 82 \\
75.9 \pm 0.2\end{array}$ & $\mathrm{~T}$ test $=23.0$ & $0.0^{*}$ \\
\hline $\begin{array}{l}\text { Waist/Hip ratio } \\
\text { Male } \\
\text { Range } \\
\text { Mean } \pm \text { SD }\end{array}$ & $\begin{array}{c}\mathrm{N}=36 \\
0.89: 0.99 \\
0.94 \pm 0.02 \\
\end{array}$ & $\begin{array}{c}\mathrm{N}=38 \\
0.81: 0.91 \\
0.88 \pm 0.1 \\
\end{array}$ & $\mathrm{~T}$ test $=7.1$ & $0.01 *$ \\
\hline $\begin{array}{l}\text { Female } \\
\quad \text { Range } \\
\text { Mean } \pm \text { SD }\end{array}$ & $\begin{array}{c}\mathrm{N}=214 \\
0.78: 0.93 \\
0.86 \pm 0.2\end{array}$ & $\begin{array}{c}\mathrm{N}=212 \\
0.74: 0.87 \\
0.79 \pm 0.3\end{array}$ & $\mathrm{~T}$ test $=6.1$ & $0.03 *$ \\
\hline
\end{tabular}

*Significant

Table 6: Distribution of Skin diseases among cases group according to BMI in comparison to control group

\begin{tabular}{|l|c|c|c|c|c|}
\hline \multirow{2}{*}{ Skin diseases } & Control & \multicolumn{4}{c|}{ Cases } \\
\cline { 2 - 6 } & $\begin{array}{c}\text { Average BMI } \\
\mathbf{N = 2 5 0}\end{array}$ & $\begin{array}{c}\text { Overweight } \\
\mathbf{N = 8 0}\end{array}$ & $\begin{array}{c}\text { Obese class 1 } \\
\mathbf{N = 9 8}\end{array}$ & $\begin{array}{c}\text { Obese class 2 } \\
\mathbf{N}=\mathbf{4 7}\end{array}$ & $\begin{array}{c}\text { Obese class 3 } \\
\mathbf{N}=\mathbf{2 5}\end{array}$ \\
\hline Planter wart & $21(8.4 \%)$ & $3(3.75 \%)$ & $1(1.02 \%)^{*}$ & & 0 \\
\hline Vitilligo & $4(1.6 \%)$ & 0 & 0 & 0 & $0(0 \%)$ \\
\hline Acne & $35(14 \%)$ & $13(16.25 \%)$ & $7(7.14 \%)$ & $6(12.8 \%)$ & $2(8 \%)$ \\
\hline Tinea pedis & $45(18 \%)$ & $38(47.5 \%)^{*}$ & $39(39.8 \%)^{*}$ & $18(38.3 \%)^{*}$ & $8(32 \%)$ \\
\hline Hair dandruff & $70(28 \%)$ & $21(26.25 \%)$ & $25(25.5 \%)$ & $13(27.66 \%)$ & $8(32 \%)$ \\
\hline Striae & $32(12.8 \%)$ & $39(48.75 \%)^{*}$ & $75(76.5 \%)^{*}$ & $37(78.7 \%)^{*}$ & $20(80 \%)^{*}$ \\
\hline Callosity & $28(11.2 \%)$ & $13(16.25 \%)$ & $7(7.14 \%)$ & $6(12.76 \%)$ & $3(12 \%)$ \\
\hline Intertrigo & $16(6.4 \%)$ & $31(38.75 \%)^{*}$ & $59(60.2 \%)^{*}$ & $29(61.7 \%)^{*}$ & $15(60 \%)^{*}$ \\
\hline Tinea versicolour & $2(0.8 \%)$ & 0 & 0 & 0 & 0 \\
\hline Skin tag & $39(15.6 \%)$ & $49(61.25 \%)^{*}$ & $58(59.18 \%) *$ & $31(65.96)^{*}$ & $15(60 \%)^{*}$ \\
\hline Hidradenitis suppurativa & 0 & 0 & $2(2.04 \%)$ & $1(2.13 \%)$ & $0(0 \%)$ \\
\hline Acanthosis negricans & 0 & $15(18.75 \%)$ & $67(68.37 \%)$ & $32(68.1 \%)$ & $20(80 \%)$ \\
\hline Lymphoedema & 0 & $2(2.5 \%)$ & $5(5.1 \%)$ & $4(8.5 \%)$ & $2(8 \%)$ \\
\hline Superficial varicose vein & $3(1.2 \%)$ & $12(15 \%) *$ & $13(13.26 \%)^{*}$ & $7(14.89 \%)^{*}$ & $5(20 \%) 0^{*}$ \\
\hline Hirsutism & $11(4.4 \%)$ & $17(21.25 \%)^{*}$ & $10(10.20 \%)^{*}$ & $8(17.02 \%)^{*}$ & $3(12 \%)$ \\
\hline Psoriasis & $7(2.8 \%)$ & $9(11.25 *$ & $9(9.18 \%)^{*}$ & $7(14.89 \%)^{*}$ & $1(4 \%)$ \\
\hline Folliculitis & 0 & $1(1.25 \%)$ & $2(2.04 \%)$ & $1(2.13 \%)$ & 0 \\
\hline *Significant & & & & \\
\hline
\end{tabular}

*Significant 
significance difference were noted between obese patients and control groups in tinea pedis, planter wart, striae, intertrigo, skin tag, planter hyperkeratosis, varicose vein, hirsutism and psoriasis. Dermatologists must work with primary health care physicians and nutritional specialists to reduce incidence of obesity or reduce the effects of obesity on the skin.

\section{Conflict of interest}

The authors declare no conflict of interest.

\section{References}

1. WHO. Obesity and Overweight. Fact sheet $\mathrm{N}^{\circ}$ 311. www.who.int/mediacentre/factsheets/fs311/ en/ (accessed 31 Dec 2015)

2. Popkin BM. Recent dynamics suggest selected countries catching up to US obesity. Am J Clin Nutr 2010;91(1):284S-8S.

3. Christina-Maria Kastorini, Haralampos J. Milionis, Aggeliki Ioannidi, Kallirroi Kalantzi, Vassilios Nikolaou, Konstantinos N. Vemmos, et $a$ l. Adherence to the Mediterranean diet in relation to acute coronary syndrome or stroke nonfatal events: a comparative analysis of a case/ case-control study. Am Heart J 2011;162:717-24.

4. Mehio Sibai A, Nasreddine L, Mokdad AH, Adra N, Tabet M, Hwalla N. Nutrition transition and cardiovascular disease risk factors in Middle East and North Africa Countries: reviewing the evidence. Ann Nutr Metab 2010;57:193-203.

5. WHO. Non communicable diseases country profile 2011: WHO Global report. www.who.int/ $\mathrm{nmh} /$ publication/ncd profiles2011/en/ (accessed 31 Dec 2015)

6. García Hidalgo L. Dermatological complications of obesity. Am J Clin Dermatol 2002;3(7):497506.

7. Clinical Methods: The History, Physical, and Laboratory Examinations. 3rd edition. Chapter 103. An Overview of the Skin and Appendages written by Marilynne McKay. Emory University School of Medicine, Atlanta, Georgia, 1990.

8. WHO. Waist Circumference and Waist-Hip Ratio: Report of a WHO Expert Consultation. Geneva: World Health Organization, 2008.

9. Chen W. Childhood obesity in Taiwan. Zhonghua Min Guo Xiao Er Ke Yi Xue Hui Za Zhi. 1997;38(6):438-42

10. Al-Mutairi N. Associated Cutaneous Diseases in Obese Adult Patients: A Prospective Study from a Skin Referral Care Center. Med Princ Pract 2011;20(3):248-52.

11. Boza, JC, Trindade E, Peruzzo J, Sachett L, Rech L, Cestari T. Skin manifestations of obesity: a comparative study. J Eur Acad Dermatol Venereol 2012;26(10):1220-3.

12. Hud JA, Cohen JB, Wagner JM, Cruz PD.
Prevalence and significance of acanthosis nigricans in an adult obese population. Arch Dermatol 1992;128: 941-4.

13. Schwartz R.A. Acanthosis nigricans. J Am Acad Dermatol 1994;31(1):1-19.

14. Araujo LM, Porto MV, Netto EM, Ursich MJ. Association of acanthosis nigricans with race and metabolic disturbances in obese women. Braz $J$ Med Bio Res 2002;35(1):59-64.

15. Al-Saeed WY, Al-Dawood KM, Bukhari IA, Bahnassy A. Dermatosis in obese female schoolchildren in the Al-Khobar area, Eastern Saudi Arabia. J Family Community Med 2006; 13 (2):65-9.

16. Sharquie, K.E, Al-Rawi J.R, Al-Tamimi F. The Frequency of Skin Disease in Obese Children and Adult Iraqi Population. Saudi Med J 2005;26 (11):1835-6.

17. Ruutiainen K, Erkkola R, Gronroos MA, Irjala $\mathrm{K}$. Influence of body mass index and age on the grade of hair growth in hirsute women of reproductive ages. Fertil Steril 1988;50:260-5.

18. Satpathy HK, Fleming A and Frey D, Barsoom M, Satpathy C, Khandalavala J. Maternal obesity and pregnancy. Postgrad Med 2008;120(3): E1-9

19. Sakai R, Matsui S, Fukushima M, Yasuda H, Miyauchi H, Miyachi Y. Prognostic factor analysis for plaque psoriasis. Dermatology 2005;211(2):103-6.

20. Naldi L, Chatenoud L, Linder D, Belloni Fortina A, Peserico A, Virgili AR, et al. Cigarette smoking, body mass index, and stressful life events as risk factors for psoriasis: results from an Italian case-control study. $J$ Invest Dermatol 2005;125(1):61-7.

21. Davidovici B, Sattar N, Prinz J, Puig L, Emery P, Barker JN, et al. Psoriasis and systemic inflammatory diseases: potential mechanistic links between skin disease and co-morbid conditions. J Invest Dermatol 2010;130(7):178596.

22. Prey S, Paul C, Bronsard V, Puzenat E, Gourraud $\mathrm{P}$, Aractingi $\mathrm{S}$, et al. Cardiovascular risk factors in patients with plaque psoriasis: a systematic review of epidemiological studies. J Eur Acad Dermatol Venereol 2010;24 Suppl 2:23-30.

23. Martalo O, Piérard-Franchimont C, Scheen A, Piérard GE. Skin diseases and obesity. Rev Med Liege 2003;58(2):73-6.

24. Boni Elewski and Antonella Tosti. Risk Factors and Comorbidities for Onychomycosis. Implications for Treatment with Topical Therapy. J Clin Aesthet Dermatol 2015;8(11): 38 -42 .

25. Vlaijnac HD, Maksimoyic MZ, Matic PA, Radak DJ. Body mass index and primary venous disease - A cross-sectional study. Eur J Vasc Endovasc Surg 2013;45(3):293-8. 